\title{
Hidrólisis Enzimática de la Proteína de Vísceras de Trucha Arco Íris (Oncorhynchus mykiss): Efecto del tipo de Enzima, Temperatura, pH y Velocidad de Agitación
}

\author{
José E. Zapata(1)*, Mariluz Moya(1) y Omar A. Figueroa(2) \\ (1) Facultad de Ciencias Farmacéuticas y Alimentarias, Dpto. de Alimentos, Universidad de Antioquia, Calle 70 \# 52-21, \\ AA1226, Medellín, Colombia (e-mail: edgar.zapata@udea.edu.co; marimoya.r@gmail.com) \\ (2) Universidad de la Guajira, Facultad de Ingeniería, Programa de Ingeniería Industrial. Riohacha. Colombia. \\ (e-mail: omfimo22@gmail.com)
}

* Autor a quien debe ser dirigida la correspondencia.

Recibido Feb. 25, 2019; Aceptado Abr. 8, 2019; Versión final Jun. 4, 2019, Publicado Dic. 2019

\begin{abstract}
Resumen
Se comparó el grado de hidrólisis (GH) de vísceras de trucha arcoiris (Oncorhynchus mykiss) usando Alcalasa 2.4L, Flavourzyme y Neutrasa. Alcalasa $2.4 \mathrm{~L}$ presentó GH más altos comparados con Flavourzyme y Neutrasa, por lo cual el proceso con Alcalasa $2.4 \mathrm{~L}$ se optimizó en función de temperatura y $\mathrm{pH}$, entregando GH máximo de $24 \%$ a pH 8,5 y $45^{\circ} \mathrm{C}$ en reactor de $500 \mathrm{~mL}$. El proceso fue escalado a un reactor de $7,5 \mathrm{~L}$, en el que se evaluó el efecto de la velocidad de agitación (75-200 RPM) y la presencia de deflectores. Los resultados indican que el modelo ajusta satisfactoriamente los valores de $\mathrm{GH}$ en los niveles analizados $\left(\mathrm{R}^{2}=\right.$ 0,96). El GH depende de $\mathrm{pH}$, temperatura, tipo de enzima, velocidad de agitación, escala de trabajo y presencia de deflectores en el reactor. Esta información es de importancia a la hora de diseñar procesos de hidrólisis enzimática de un sustrato específico.
\end{abstract}

Palabras clave: vísceras de trucha; proteína de pescado; grado de hidrólisis; diseño factorial; $\mathrm{pH}$

\section{Enzymatic Hydrolysis of Protein of Rainbow Trout Viscera (Oncorhynchus mykiss). Effect of Type of Enzyme, Temperature, $\mathrm{pH}$ and Stirring Speed}

\begin{abstract}
The degree of hydrolysis $(\mathrm{DH})$ of rainbow trout viscera (Oncorhynchus mykiss) using Alcalase 2.4L, Flavourzyme and Neutrase. Alcalase 2.4L presented higher DH compared with Flavourzyme and Neutrase. Therefore, the process using Alcalasa $2.4 \mathrm{~L}$ was optimized according to temperature and $\mathrm{pH}$, finding a maximum $\mathrm{DH}$ of $24 \%$ at $\mathrm{pH} 8.5$ and $45^{\circ} \mathrm{C}$ in a $500 \mathrm{~mL}$ reactor. The process was scaled to a reactor of $7.5 \mathrm{~L}$, in which the effects of the the stirring speed (75-200 RPM) and the presence of deflectors were evaluated. The results indicate that the model satisfactorily fits the $\mathrm{DH}$ values in the levels analyzed $\left(\mathrm{R}^{2}=0.96\right)$. The $\mathrm{DH}$ depends on $\mathrm{pH}$, temperature, type of enzyme, speed of agitation, work scale and presence of baffles in the reactor. This information is of importance for designing the enzymatic hydrolysis processes of an specific substrate.
\end{abstract}

Keywords: rainbow trout viscera; fish protein; degree of hydrolysis; factorial design; $\mathrm{pH}$ 


\section{INTRODUCCIÓN}

La producción piscícola representa el sector agropecuario más importante del mundo, pues se estima que cada vez más personas dependen de la producción, captura, procesamiento y comercialización de productos acuícolas para su sustento. Es además, una importante fuente de proteína animal para el consumo humano, especialmente en los países en desarrollo (Dekkers et al., 2011). Sin embargo en la industria de procesamiento de pescado el $60 \%$ de la producción corresponde a los residuos y solo el $40 \%$ se destina al consumo humano directo (Dekkers et al., 2011). Los residuos se componen principalmente de restos de fileteo $(15-20 \%)$, piel y aletas (1-3\%), huesos (9-15\%), cabezas (9-12\%), vísceras (12-18\%) y escamas $(5 \%)$ (Martínez-Alvarez et al., 2015). Los cuales, a pesar de ser ricos en proteínas, la mayoría de las veces son descartados sin ningún intento de recuperación o destinados a alimentación animal, harina de pescado o fertilizantes (Deraz; 2014).

Entre los métodos propuestos para el tratamiento de los residuos sólidos procedentes de la pesca, destaca la hidrólisis de las proteínas, debido a su posibilidad de entregar compuestos de alto valor agregado como son los péptidos bioactivos (Liu et al., 2014). Sin embargo los primeros procesos de hidrólisis químicas y extracción con solventes orgánicos, afectan la calidad nutricional de las proteínas y deterioran los aminoácidos. Para lograr procesos de hidrólisis más controlados y reproducibles, se han venido aplicando cada vez más enzimas comerciales para la obtención de hidrolizados proteicos a partir de residuos de pescado (Shahidi y Ambigaipalan; 2015). Estos procesos han mostrado ventajas que se relacionan con las características generales de las enzimas utilizadas, tales como mayor selectividad de sustratos, realización de procesos en condiciones térmicas menos drásticas y fácilmente controlables, lo que minimiza el desarrollo de reacciones secundarias alterantes manteniendo, por lo tanto, el valor nutricional del producto. Es así como se han utilizado en hidrólisis de subproductos de pescado enzimas como Alcalasa, papaína, pepsina, tripsina, pancreatina, Flavourzyme, pronasa, Neutrasa, protamex y termolisina (Saidi et al., 2015).

Los hidrolizados de proteína de subproductos acuícolas, poseen un excelente equilibrio en aminoácidos, buena digestibilidad y rápida absorción,presentan ciertas propiedades tecno-funcionales (He et al., 2013), contienen ácidos grasos omega-3 (Silva et al., 2014) y además pueden ser fuente de péptidos bioactivos (Liu et al., 2014). Estos péptidos dependiendo de su composición, secuencia y número de aminoácidos (generalmente entre 2 - 20), pueden presentar actividades quelantes de Zinc (Zhu et al., 2015), antimicrobianos (Haney E. et al., 2016), antioxidantes y antihipertensivos (Chuesiang y Sanguandeekul, 2015), inmunomoduladora, antitrombótica, anticancerígena, entre otras (Deraz, 2014; Shahidi y Ambigaipalan, 2015). Diferentes investigaciones han establecido la relación existente entre la actividad biológica y el peso molecular de los péptidos (Liu et al., 2014). Particularmente son de interés para usos nutricionales y/o farmacéuticos, las fracciones de péptidos con pesos moleculares entre 1 - 4kDa (Morales-Medina, et al; 2017). Por lo tanto, obtener hidrolizados con altos grados de hidrólisis (GH), incrementa la posibilidad de obtener péptidos Bioactivos.

Cuando se quiere llevar un proceso de reacción de una escala a otra, se debe garantizar que la reacción en la escala mayor, alcance los mismos resultados en cuanto a eficiencia y calidad de los productos obtenidos. Aspecto que ha sido poco estudiado a pesar del innegable avance que se ha alcanzado en el estudio de la hidrólisis de proteínas de pescado. Usualmente el escalado se basa en el llamado "principio de similitud, biológica, química y geométrica", donde las diferencias en las propiedades entre los dos sistemas, mantienen una relación constante y la reacción se lleva a cabo bajo las mismas condiciones. Uno de los criterios de escalado más utilizados es el del mantenimiento del número de Reynolds (Re) (Gelves and et al. 2013) y sus combinaciones con el punto de operación (Palmqvist and et al. 2016), como se indica en la ecuación (1).

$$
\operatorname{Re}_{\mathrm{M}}=\operatorname{Re}_{\mathrm{p}} \rightarrow\left(\frac{\mathrm{N} \cdot \mathrm{D}_{\mathrm{i}}^{2} \cdot \rho}{\mu}\right)_{\mathrm{m}}=\left(\frac{\mathrm{N} \cdot \mathrm{D}_{\mathrm{i}}^{2} \cdot \rho}{\mu}\right)_{\mathrm{p}}
$$

El objeto del presente estudio fue analizar el efecto de proteasas comerciales (Alcalasa, Flavourzyme y Neutrasa) en la hidrólisis de vísceras de Trucha arcoíris (Oncorhynchus mykiss), evaluando el rendimiento en la ruptura de enlaces peptídicos a través del GH. Del mismo modo, establecer las condiciones de hidrólisis que maximicen el GH en función del pH y la temperatura y evaluar el efecto de la velocidad de agitación sobre el GH de la enzima con mayores valores de este parámetro. Adicionalmente se escaló el proceso llevando el sistema de reacción de $500 \mathrm{~mL}$ (modelo) a 7,5L (prototipo), evaluando el efecto de la velocidad de agitación y el uso de deflectores en el reactor, sobre el GH obtenido en el prototipo.

\section{MATERIALES Y MÉTODOS}

La metodología seguida para la ejecución del presente estudio, se detalla a continuación, indicando los materiales procedimiento y técnicas empleadas. 


\section{Manejo de Materiales}

El sustrato usado en este estudio fue víscera de Trucha arcoíris (Oncorhynchus mykiss) (VTA) suministradas por la truchera San Felix del departamento de Antioquia. Las vísceras se trasladaron manteniendo la cadena de frío $\left(4^{\circ} \mathrm{C}\right)$ hasta el laboratorio, donde se calentaron a $90^{\circ} \mathrm{C}$ por 20 min para extraer parte de la grasa e inactivar las enzimas endógenas. Luego el material fue homogenizado utilizando un procesador de alimentos (Black \& Decker, USA) y posteriormente almacenado a $-20^{\circ} \mathrm{C}$ hasta su uso. Las vísceras fueron caracterizadas a través de análisis bromatológicos: el contenido de humedad según la norma AOAC 930.15 (AOAC, 1990), el extracto etéreo según la AOAC 960.39 (AOAC, 1990), las cenizas según la AOAC 920.153 (AOAC, 1990) y la proteína con base en la AOAC 954.01 (AOAC, 1990). Todos los reactivos usados fueron de grado analítico.

\section{Enzimas comerciales}

Para la hidrólisis se utilizaron tres enzimas comerciales grado alimenticio: Alcalasa 2.4L (2,4 AU-A/g), enzima proteolítica producida por fermentación sumergida de una cepa seleccionada de Bacillus licheniformis, con temperaturas de trabajo entre $45^{\circ}-65^{\circ} \mathrm{C}$ y pH entre $7,5-9,5$, dependiendo del tipo de sustrato (Belén Camacho et al., 2007). Neutrasa 1,5MG (1,5 AU-NH/g), enzima proteolítica producida por fermentación sumergida de una cepa seleccionada de Bacillus subtilis, con temperaturas de trabajo entre $45^{\circ}-65^{\circ} \mathrm{C}$ y $\mathrm{pH} 7,5-9,5$. Flavourzyme 500MG (500 LAPU/g), complejo de proteasa fúngica y peptidasa producido por fermentación sumergida de una cepa seleccionada de Aspergillus oryzae, contiene tanto actividades de endoproteasa como de exopeptidasa, $\mathrm{pH}$ de trabajo entre 5,0-8,0 y temperatura entre $50-60^{\circ} \mathrm{C}$ (Dekkers et al., 2011).

\section{Sistema de reacción}

Se empleó un reactor de vidrio de $500 \mathrm{~mL}$, con camisa de circulación de agua para regular la temperatura. La agitación se mantuvo constante en $450 \mathrm{rpm}$, por medio de un agitador magnético (Metrohm 801). El control de $\mathrm{pH}$ se realizó con un electrodo de diafragma esmerilado fijo (temperatura entre $0-80{ }^{\circ} \mathrm{C}$ ), conectado a un titulador automático Titrando 842 (Metrohm, Suiza), todo el sistema fue operado con el software tiamo 1.2.1. (Metrohm, Suiza).

Las mejores condiciones obtenidas en el reactor de $500 \mathrm{~mL}$ (modelo) con la Alcalasa 2.4L, fueron escaladas a un Biorreactor New Brunswick $\AA$ de 7,5 L (prototipo), con un volumen de trabajo de $5 \mathrm{~L}$, equipado con 2 turbinas Rushton en el sistema de agitación y bafles deflectores para control de turbulencias. Teniendo en cuenta que el sustrato en el modelo y en el prototipo es el mismo, la expresión en la ecuación (1), se puede simplificar como aparece en la ecuación (2).

$$
\left(\mathrm{N} . \mathrm{D}_{\mathrm{i}}^{2}\right)_{\mathrm{m}}=\left(\mathrm{N} \cdot \mathrm{D}_{\mathrm{i}}^{2}\right)_{\mathrm{p}}
$$

Para este caso $N_{M}=7,66 \mathrm{~s}^{-1}, D_{i, m}=5 \mathrm{~cm}, D_{i, p}=7,7 \mathrm{~cm}$, por lo que despejando $N_{p}$ de la ecuación (2) se obtiene una velocidad del impulsor en el prototipo de $200 \mathrm{rpm}$. Una vez escalado el proceso, se evalúo el efecto de la presencia de deflectores sobre el $\mathrm{GH}$, utilizando las mejores condiciones que se habían encontrado en las demás variables del proceso.

\section{Hidrólisis enzimática de vísceras}

Para la hidrólisis, $450 \mathrm{~g}$ de vísceras procesadas (10,17\% en proteína) se mezclaron con agua destilada en relación $1: 1(\mathrm{~m} / \mathrm{v})$, para reducir la viscosidad del medio y facilitar el acceso de la enzima al sustrato. Se usó una concentración de enzima de $1 \%$ respecto a las vísceras, $5 \%(\mathrm{~g} / 100 \mathrm{~mL})$ de proteína, mientras que el pH y la temperatura se ajustaron según los niveles definidos en el diseño experimental. Cada ensayo tuvo una duración de $5,5 \mathrm{~h}$, tomando registros del volumen de base gastada cada $5 \mathrm{~min}$. Al finalizar el proceso de hidrólisis, se realizó inactivación térmica de la enzima a $95^{\circ} \mathrm{C}$ por $15 \mathrm{~min}$.

\section{Determinación del grado de hidrólisis}

La reacción se monitoreó por medio del GH, expresado como la relación entre el número de enlaces peptídicos hidrolizados $(h)$ y el número de enlaces peptídicos totales en la proteína nativa por unidad de peso ( $h_{\text {tot }}$ ) (AdlerNissen, 1986). Para ello se utilizó el método del pH-stat, el cual consiste en mantener constante el pH del medio de reacción con adición de una solución básica (hidróxido de sodio $2.0 \mathrm{~N}$ ). Dado que a medida que la hidrólisis avanza en medio alcalino, el grupo carboxilo terminal se disocia por comple y los protones formados se reparten de acuerdo con el equilibrio de protonación de los grupos a-amino liberados. La base agregada para mantener constante el pH neutraliza únicamente los protones que son sustituidos por el catión de la base 
(Adler-Nissen, 1986). El consumo de base puede relacionarse con el GH según las ecuaciones (3-5) (Forghani et al., 2012).

$$
\begin{aligned}
& \mathrm{GH}=\frac{\mathrm{V}_{\mathrm{B}^{\star}} \mathrm{N}_{\mathrm{B}}}{\mathrm{M}_{\mathrm{P}} * \alpha * h t o t} \times 100 \\
& \mathrm{\alpha}=\frac{10^{\mathrm{pH}-\mathrm{pK}}}{1+10^{\mathrm{pH}-\mathrm{pK}}} \\
& \mathrm{pK}=7,8+\frac{(298-\mathrm{T})}{298^{*} \mathrm{~T}} 2400
\end{aligned}
$$

Para las proteínas de pescado, ha sido usado un valor de htot de 8,6 Eq/kg (Adler-Nissen, 1986; Kechaou et al., 2009). Por su parte el a en la ecuación (4) depende del pK, que a su vez es función de la temperatura, en la forma que se aprecia en la ecuación (5).

\section{Diseño de experimentos}

Con el objetivo de seleccionar la enzima con mayor GH, se evaluaron tres enzimas (Alcalasa, Neutrasa y Flavourzyme), utilizando valores de $\mathrm{pH}$ y temperatura, definidos con base en la literatura (Kechaou, et al., 2009) y en ensayos preliminares (tabla 1). A partir de estos resultados se seleccionó la enzima con mayor GH y con esta se desarrolló un diseño experimental central compuesto, que permitió maximizar el GH en función del $\mathrm{pH}$ (entre los niveles 7,5-9,5) y la temperatura (entre los niveles $45-65{ }^{\circ} \mathrm{C}$ ). El análisis del diseño experimental y la optimización se realizaron empleando el software Desing Expert 8.0.7.1 (Stat-Ease Inc, USA), que basa su optimización numérica en la función de deseabilidad, la cuales la media geométrica (multiplicativa) de todos las deseabilidades individuales en un rango de 0 (mínimo) a 1 (máximo), con lo que es el resultado de la optimización simultanea de varias variables de respuesta.

\section{Tabla 1: Comparación del GH obtenido a través de hidrólisis con diferentes enzimas}

\begin{tabular}{|l|c|c|c|}
\hline Enzima & $\mathrm{pH}$ & $\mathrm{T}\left({ }^{\circ} \mathrm{C}\right)$ & $\mathrm{GH}(\%)$ \\
\hline \multirow{4}{*}{ Neutrasa } & 7,5 & 45 & 7,47 \\
\cline { 2 - 4 } & 8,5 & 45 & 6,48 \\
\cline { 2 - 4 } & 7,5 & 55 & 4,39 \\
\cline { 2 - 4 } & 7,5 & 65 & 2,2 \\
\hline \multirow{4}{*}{ Flavourzyme } & 8 & 40 & 4,37 \\
\cline { 2 - 4 } & 7,5 & 45 & 5,39 \\
\cline { 2 - 4 } & 8,5 & 45 & 5,36 \\
\cline { 2 - 4 } & 7,5 & 55 & 3,75 \\
\hline \multirow{5}{*}{ Alcalasa } & 8,5 & 55 & 2,41 \\
\cline { 2 - 4 } & 9,5 & 55 & 12,61 \\
\cline { 2 - 4 } & 7,5 & 45 & 7,53 \\
\cline { 2 - 4 } & 8,5 & 45 & 15,16 \\
\cline { 2 - 4 } & 7,5 & 55 & 16,45 \\
\cline { 2 - 4 } & 7,5 & 65 & 12,27 \\
\hline
\end{tabular}

\section{RESULTADOS Y DISCUSIÓN}

Los resultados tabulados y en diagramas se muestran a continuación paralelamente con la discusión de los mismos.

\section{Análisis químico proximal de las vísceras}

La composición química proximal de las vísceras sin procesar fue: humedad 56,93 \%, proteína cruda del $9,14 \%$, grasa del $38,15 \%$ y ceniza total $1,51 \%$. El pH fue 5,84, que está en el rango usual de vísceras de pescado, como ya lo señalaron Bhaskar y Mahendrakar en 2008, quienes además obtuvieron humedades superiores $(76,25 \%)$ para vísceras de Catla Catla, pero valores similares de proteína $(8,52 \%)$ y valores inferiores de grasa $(12,46 \%)$, así como un contenido superior de ceniza $(2,50 \%)$. Sin embargo, las diferencias 
entre la composición de las vísceras de las dos especies pueden deberse a la influencia de factores tales como el sexo, la edad, la zona de captura y la época del año, así como el estado nutricional y la temperatura del agua, lo cual define el tiempo de cosecha (Chuesiang y Sanguandeekul, 2015). La baja proporción de ceniza se debe a que están desprovista de espinas y escamas. El contenido de proteínas de las vísceras de trucha encontradas en este estudio, representa un valor de interés para su recuperación y aprovechamiento, máxime cuando se tiene un valor de humedad tan considerable que puede ser retirado con procesos de secado y de esa forma obtener un sustrato con un alto contenido de proteína. Por su parte las vísceras

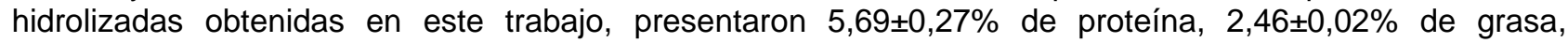
$88,54 \pm 0,13 \%$ de humedad y $3,17 \pm 0,02 \%$ de cenizas, cuyos cambios con respecto a las vísceras frescas se deben principalmente a la eliminación de grasa que se les realizó $\left(90^{\circ} \mathrm{C}\right.$ por $\left.20 \mathrm{~min}\right)$.

\section{Selección de la enzima con mayor GH}

En la Tabla 1 se muestran los resultados experimentales obtenidos para el GH de cada enzima en las diferentes condiciones de $\mathrm{pH}$ y temperatura analizadas. Se evidencia que la Alcalasa 2.4L presenta GH más altos comparados con Flavourzyme y Neutrasa para todas las combinaciones de $\mathrm{pH}$ y temperaturas evaluadas, lo cual puede deberse a que las proteasas alcalinas, entre las que se encuentra la Alcalasa $2.4 \mathrm{~L}$, muestran actividades mayores que las proteasas neutras, como Flavourzyme y Neutrasa, cuando actúan sobre proteínas de pescado. Esto tiene importancia si se considera que el mayor grado de hidrólisis en estos sustratos, puede estar asociado al incremento de los niveles de aminoácidos esenciales y por ende del valor nutricional de los productos alimenticios derivados de los mismos (Kechaou, et al., 2009). Adicionalmente, altos grados de hidrólisis de subproductos pesqueros se han relacionado con mayor capacidad de captura de radicales y mayor capacidad reductora de los hidrolizados. En general se ha documentado ampliamente la relación existente entre bajos pesos moleculares de péptidos y la actividad biológica (Liu et al., 2014). Las aplicaciones más interesantes en este aspecto se han encontrado en péptidos con pesos moleculares entre $1-4$ kDa (Saidi et al., 2015). En muchos casos el GH, resulta ser una herramienta indirecta para describir la distribución del peso molecular de los hidrolizados, en el sentido que una prolongada hidrólisis redunda casi siempre en grados de hidrólisis altos y por tanto tamaños peptídicos mucho más pequeños (Morales-Medina, et al; 2017).

\section{Efecto del pH y la temperatura sobre el GH en la hidrólisis enzimática con Alcalasa}

Con base en los resultados de la primera fase, se seleccionó la Alcalasa 2.4L, como la enzima de trabajo para la hidrólisis enzimática de vísceras de Trucha arcoíris (Oncorhynchus mykiss), por lo cual se planteó evaluar el efecto que tienen el $\mathrm{pH}$ y la temperatura sobre el $\mathrm{GH}$ obtenido con esta enzima. Para ello se aplicó un diseño experimental central compuesto con 4 puntos centrales, del cual se presenta en la tabla 2, las corridas experimentales.

Tabla 2. Datos del Diseño central compuesto obtenidos con Alcalasa 2.4L y Vísceras de trucha en reactor de $500 \mathrm{~mL}$

\begin{tabular}{|c|c|c|}
\hline \multicolumn{2}{|c|}{ Variables Independientes } & Respuesta \\
\hline $\mathrm{T}\left({ }^{\circ} \mathrm{C}\right)$ & $\mathrm{pH}$ & $\mathrm{GH}(\%)$ \\
\hline 45 & 7,5 & 18,61 \\
\hline 55 & 7,5 & 16,45 \\
\hline 65 & 7,5 & 23,7 \\
\hline 45 & 8,5 & 24,17 \\
\hline 55 & 8,5 & 20,51 \\
\hline 55 & 8,5 & 20,42 \\
\hline 55 & 8,5 & 20,01 \\
\hline 55 & 8,5 & 19,12 \\
\hline 55 & 8,5 & 18,79 \\
\hline 65 & 8,5 & 18,96 \\
\hline 45 & 9,5 & 17,11 \\
\hline 55 & 9,5 & 19,44 \\
\hline 65 & 9,5 & 21,69 \\
\hline
\end{tabular}

En la Tabla 3, se muestra el análisis de varianza (ANOVA) del diseño y en la ecuación 6, el modelo ajustado con los términos significativos. En ella se observa significancia estadística del modelo $(<0.05)$, el $R^{2}(0.96)$ y la no significancia para la falta de ajuste del mismo $(p=0,5961)$. El análisis de varianza (ANOVA) demuestra que el polinomio representa adecuadamente los datos experimentales, teniendo en cuenta que el $\mathrm{R}^{2}$ es cercano a 1. Esto indica que el modelo obtenido, describe la influencia de las variables independientes sobre 
el GH de las proteínas de vísceras de trucha en un porcentaje satisfactorio. Esto también permite observar los efectos significativos de los factores y sus interacciones, así como el signo que estos efectos tienen sobre la respuesta. Se observa que ambas variables tienen efectos significativos tanto en sus términos lineales y cuadráticos, como sus interacciones, a excepción de la lineal $\mathrm{pH}^{\star} \mathrm{T}$.

Tabla 3. Análisis de varianza del diseño estadístico (ANOVA)

\begin{tabular}{|l|c|c|c|c|}
\hline \multicolumn{1}{|c|}{ Fuente } & $\begin{array}{c}\text { Suma de } \\
\text { cuadrados }\end{array}$ & $\begin{array}{c}\text { Media de } \\
\text { cuadrados }\end{array}$ & Valor- $\mathrm{f}$ & Valor - P \\
\hline Modelo & 58,2 & 8,31 & 15,93 & 0,0038 \\
\hline$T:$ Temperatura & 13,57 & 13,57 & 26 & 0,0038 \\
\hline$p H$ & 4,47 & 4,47 & 8,56 & 0,0328 \\
\hline$T^{*} p H$ & 0,065 & 0,065 & 0,12 & 0,7385 \\
\hline$T^{2}$ & 11,66 & 11,66 & 22,33 & 0,0052 \\
\hline$p H^{2}$ & 6,77 & 6,77 & 12,97 & 0,0155 \\
\hline$T^{2} p H$ & 7,51 & 7,51 & 14,38 & 0,0127 \\
\hline TpH & 33,63 & 33,63 & 64,44 & 0,0005 \\
\hline $\begin{array}{l}\text { Prueba falta } \\
\text { ajuste }\end{array}$ & 0,2 & 0,2 & 0,33 & 0,5961 \\
\hline
\end{tabular}

En la Fig. 1, se muestra la superficie de respuesta que ilustra los efectos principales e interacciones de los factores sobre el $\mathrm{GH}$. En ella se observa como el efecto de la temperatura sobre $\mathrm{GH}$ cambia dependiendo del valor de $\mathrm{pH}$ de trabajo. Cuando la reacción tiene lugar en condiciones extremas de $\mathrm{pH}(7,5$ ó 9,5), un aumento de la temperatura tiende a favorecer el $\mathrm{GH}$, pero en la región central $(\mathrm{pH} 8,5)$, estos aumentos de temperatura reducen el $\mathrm{GH}$. En tanto que las mejores condiciones de reacción (GH más altos) se presentan en la región central de $\mathrm{pH}$ y temperaturas más bajas del diseño. Se sabe que cambios en el pH afectan tanto al sustrato como a la enzima, porque cambian la distribución de cargas y la conformación de las proteínas (Roslan et al., 2015). Además, el pH influencia la disociación de grupos activos de la enzima, afectando la dinámica de asociación de ésta con el sustrato (Shi et al., 2005). Por su parte la temperatura tiene efecto sobre cualquier proceso químico o bioquímico debido a que un incremento de temperatura aumenta la energía cinética a las moléculas, pero debido a la naturaleza proteica de las enzimas su estructura terciaria se ve comprometida cuando se alcanzan elevadas temperaturas, lo que conduce a la pérdida de actividad catalítica (Pérez-Gálvez et al., 2011), que se traduce en una disminución del GH cuando se trabaja por encima de un cierto límite de temperatura.

El resultado particular puede ser explicado si tenemos en cuenta que en muchas reacciones enzimáticas, el $\mathrm{pH}$ de operación conlleva a cambios en los reactivos, entre ellos la posible desnaturalización de la estructura de la proteína de la enzima o la alteración del carácter iónico de los sustratos. Este posible efecto de desnaturalización que ocurre a pH extremos en nuestra reacción, puede verse compensada con la mejora en la actividad enzimática ocurrida a medida que sube la temperatura y de otro lado una disminución en la misma, puede favorecer interacciones iónicas con el sustrato que mejoran el rendimiento. Sin embargo el efecto puede no ser el mismo para otros sustratos, en su estudio Salwanee et al. (2013) obtuvieron altos GHs hidrolizando vísceras de atún con Alcalase en un rango de $\mathrm{pH}=7-9$, aunque no encontraron cambios significativos en el porcentaje de $\mathrm{GH}$ entre estos valores de $\mathrm{pH}$.

$$
\mathrm{GH}=-1421,39+426,64^{*} \mathrm{pH}+11,69{ }^{*} \mathrm{~T}-5,94^{*} \mathrm{pH}^{*} \mathrm{~T}-29,18 * \mathrm{pH}^{2}+0,22{ }^{*} \mathrm{~T}^{2}+0,5 \text { * } \mathrm{pH}^{2}{ }^{*} \mathrm{~T}-0,02{ }^{*} \mathrm{pH}^{*} \mathrm{~T}^{2}
$$

\section{Maximización del $\mathrm{GH}$}

El modelo que se presenta en la ecuación 6, se sometió a una rutina de optimización maximizando el GH en función de $\mathrm{pH}$ y temperatura. Los valores óptimos obtenidos fueron $\mathrm{pH} 8,5$ y temperatura $45^{\circ} \mathrm{C}$, para un valor de $\mathrm{GH}$ predicho de 24,17\%. La corroboración experimental de estas condiciones entregó valores del GH de $24,12 \%$ (3 réplicas), lo que demuestra la validez del modelo obtenido para predecir el comportamiento del GH en el rango de estudio. Los valores de GHs superan los encontrados por Gbogouri et al. (2004), quienes obtuvieron valores de GH entre $11,5-17,3 \%$, trabajando entre $49-61^{\circ} \mathrm{C}$, en la hidrólisis de cabezas de salmón con Alcalasa. Además, de los de Souissi et al. (2007) quienes describieron hidrólisis de proteínas con GH de 6,$62 ; 9,31$ y $10,16 \%$ a partir de cabezas y vísceras de sardinella (Sardinella aurita) por tratamiento con Alcalasa. En todo caso éstos autores no llevaron a cabo análisis de optimización y trabajaron en rangos de $\mathrm{T}$ y $\mathrm{pH}$ bastante cercanos a los óptimos encontrados en este trabajo: $\mathrm{pH} 8$ y $\mathrm{T}$ de $50^{\circ} \mathrm{C}$. Esto demuestra la importancia de aplicar procesos de optimización en la hidrólisis enzimática, puesto que factores como pH y temperatura, tienen efectos preponderantes sobre el desarrollo de las reacciones hidrolíticas. 
Otros estudios de optimización de hidrólisis de proteínas de pescado usando Alcalasa, han reportado temperaturas óptimas de $50^{\circ} \mathrm{C}$ (Roslan et al., 2015), $55^{\circ} \mathrm{C}$ (See et al. 2011) y $60^{\circ} \mathrm{C}$ (Amiza et al. 2011). En cuanto al pH, se debe considerar que el rango reportado para Alcalasa está entre 6-10, siendo el valor óptimo dependiente del sustrato usado (Amiza et al., 2011; See et al., 2011).

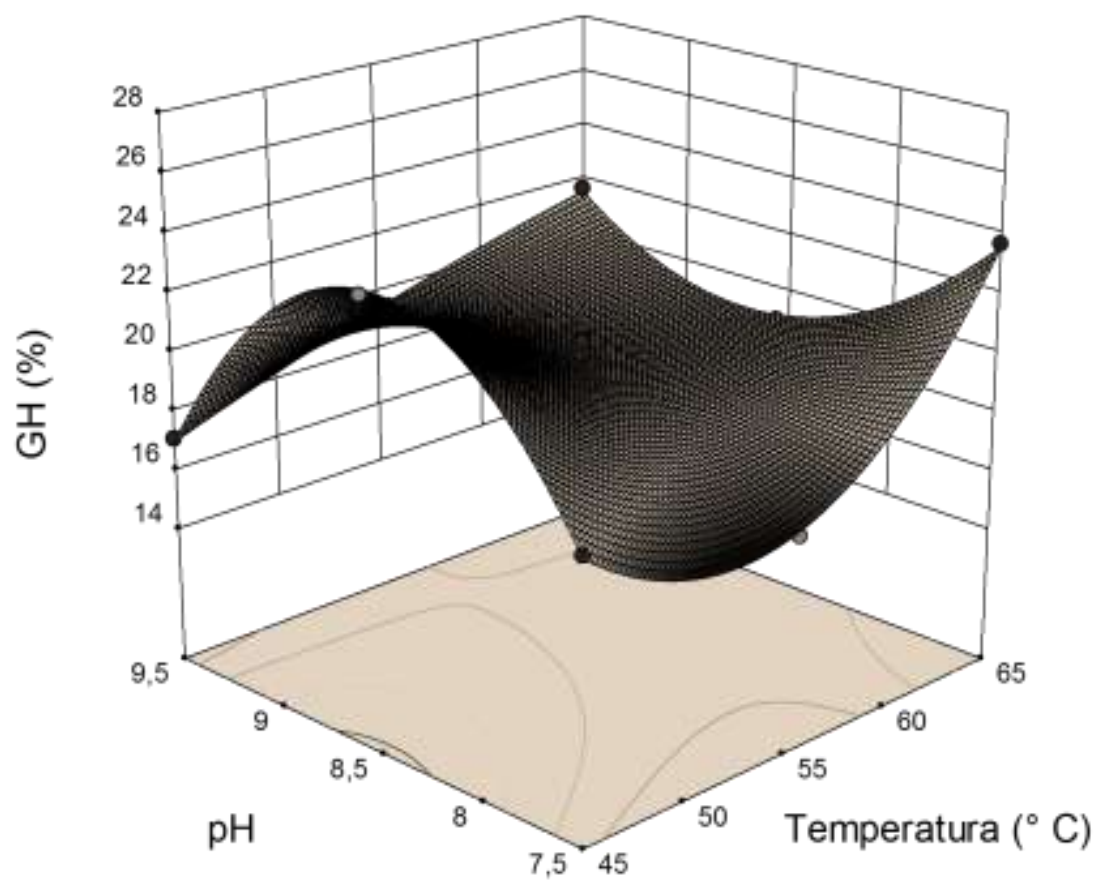

Fig. 1. Superficie de respuesta para el GH en función de temperatura y pH durante la hidrólisis enzimática

Efecto del cambio de escala sobre el GH

En la Fig. 2 se presenta el comportamiento del GH en la hidrólisis enzimática de vísceras de trucha arcoiris (Oncorhynchus mykiss) usando Alcalasa 2.4L en el reactor de 7,5 L. Se observa que el valor de $200 \mathrm{rpm}$ entrega un GH final de alrededor de $11 \%$, el cual está muy por debajo del obtenido para las condiciones óptimas en el reactor de $500 \mathrm{~mL}$. Por tal razón se decidió modificar la velocidad de agitación para mirar cómo se afectaba el valor de $\mathrm{GH}$ a las condiciones del reactor de 7,5 L, utilizando 2 turbinas Rushton en el sistema de agitación y bafles deflectores para control de turbulencias. Es de notar que para cada velocidad de agitación evaluada el GH en la reacción fue esencialmente distinto. Mejorando en seis puntos porcentuales de $\mathrm{GH}$, a medida que las revoluciones bajan de 200 hasta $100 \mathrm{rpm}$. En contraste, los experimentos realizados a 75 RPM muestran GHs mucho más bajo que los alcanzados a 100 rpm. Sin embargo, en el reactor de 7,5L, los valores de GH estuvieron por debajo los obtenidos en el de $500 \mathrm{~mL}$, por lo que se observa un efecto negativo del escalado sobre la reacción de hidrólisis, posiblemente por los cambios en la geometría del sistema, pero también por efecto de los cambios en la fluido dinámica, puesto que esta enzima presenta una alta sensibilidad a estos aspectos (Gómez y Zapata, 2017).

Aquí se evidencia además que la velocidad de 100 rpm muestra, no solo el mejor GH final, en el reactor de $7,5 \mathrm{~L}$, sino una velocidad inicial más pronunciada, donde cerca del $70 \%$ de la reacción se lleva a cabo en la primera hora. Mientras que, en la menor y mayor velocidad analizada (75 y $200 \mathrm{rpm}$ ), poco menos del $50 \%$ de reacción ocurre a la primera hora y de ahí en adelante la reacción en términos de ruptura de enlaces peptídicos, parece desacelerase de forma pronunciada en estos dos casos, con efectos más graves a 200 rpm, puesto que la curva expresa un comportamiento lineal casi las $3 / 4$ partes del tiempo total de la reacción.

Lo que ocurre se puede explicar si se tiene en cuenta que un aumento sustancial en las revoluciones de agitación, pueden llegar a favorecer el desarrollo de la reacción, posiblemente porque ayuda a mantener una mayor homogeneidad en la muestra favoreciendo el contacto enzima-sustrato. Sin embargo por encima de un cierto valor de velocidad, se ejerce un efecto negativo sobre el auge de la reacción asociado a un cambio conformacional de la Alcalasa 2.4L, que dificulta la interacción enzima-sustrato temporalmente o conlleva a un proceso de inactivación-agregación de la enzima (Gómez y Zapata, 2017). Al respecto algunos aportes en literatura científica reportan evidencia experimental que sugiere, inactivación enzimática debido al incremento en la velocidad de agitación por efectos hidrodinámicos (Colombié et al., 2001). 


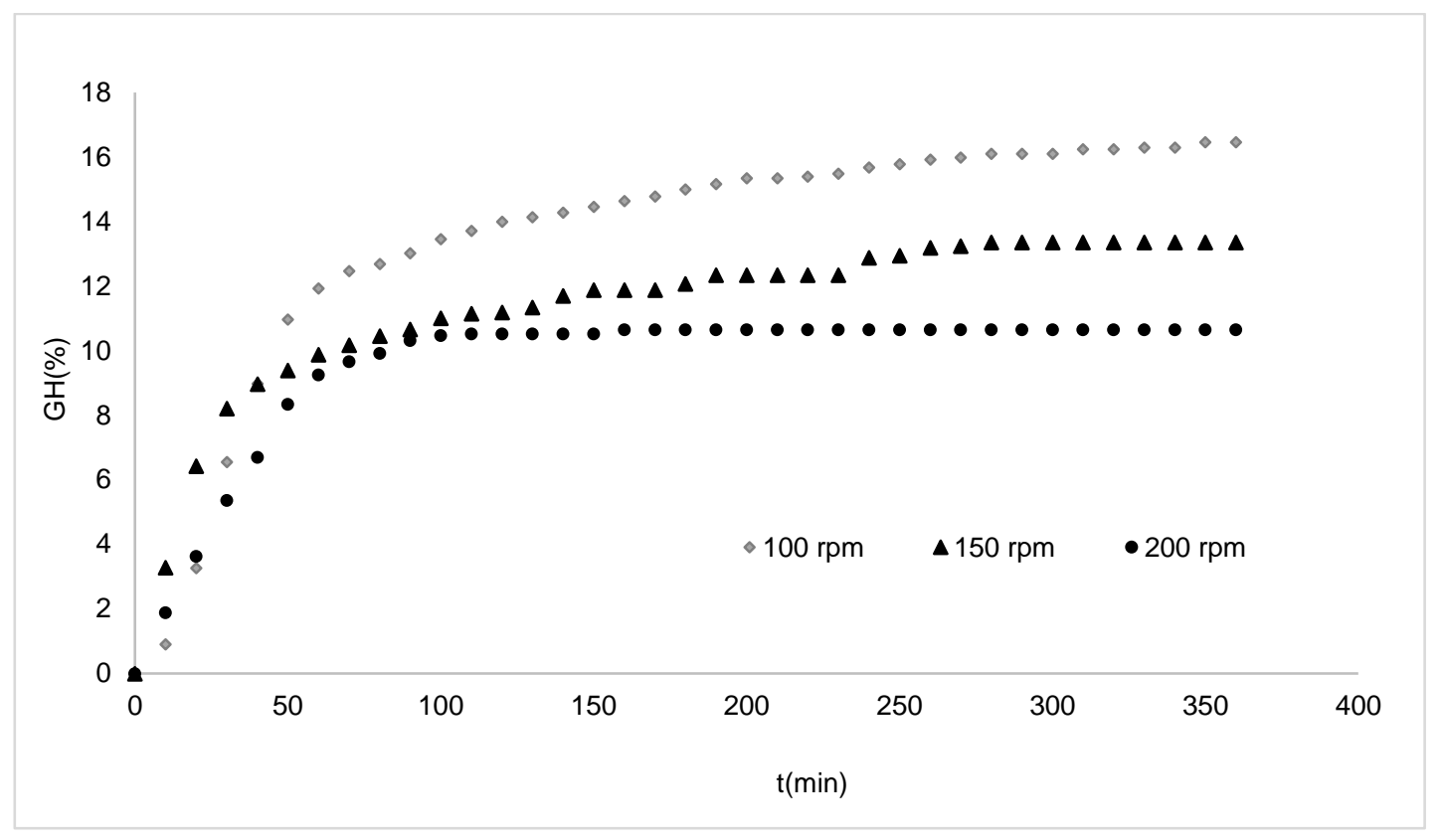

Fig. 2. Efecto de la velocidad de agitación sobre el $\mathrm{GH}$ en la hidrólisis enzimática de VTA con Alcalasa 2.4L en función del tiempo $\left(\mathrm{T}=45^{\circ} \mathrm{C}\right.$ y $\left.\mathrm{pH}=8,5\right)$ en reactor de $7,5 \mathrm{~L}$.

Efecto de los bafles sobre el GH

Para analizar el efecto del rendimiento del proceso de reacción considerando los volúmenes muertos en el sistema de mezcla por deslizamiento de partículas de fluido entre las paredes y el impulsor, se emplearon dos deflectores en el reactor agitado de 7,5 L. Los resultados se muestran en la Fig. 3, en la que se puede notar que no parece existir diferencia entre los GH alcanzados los primeros 40 minutos de la reacción. Sin embargo, el rendimiento final para el reactor sin bafles, está aproximadamente en un $50 \%$ por debajo del que si los tiene, al cabo de seis horas de reacción. Posiblemente por la presencia de volúmenes muertos en el sistema, que se deslizan al mismo tiempo que el impulsor, entre este y las paredes del tanque.

Además, se debe tener en cuenta que la reacción llevada a cabo con deflectores solo aumenta 4 puntos porcentuales desde los 90 minutos hasta las seis horas de hidrólisis. La evidencia científica sugiere que la agitación no induce la escisión de moléculas enzimáticas durante la inactivación, pero si es de esperar fenómenos de inactivación que se expresan de forma proporcional a la potencia que imparte el impulsor (Colombié et al., 2001) y posiblemente en este caso, los deflectores puedan favorecer la inactivación y la agregación al aumentar la adsorción/desorción de las enzimas en la interface.

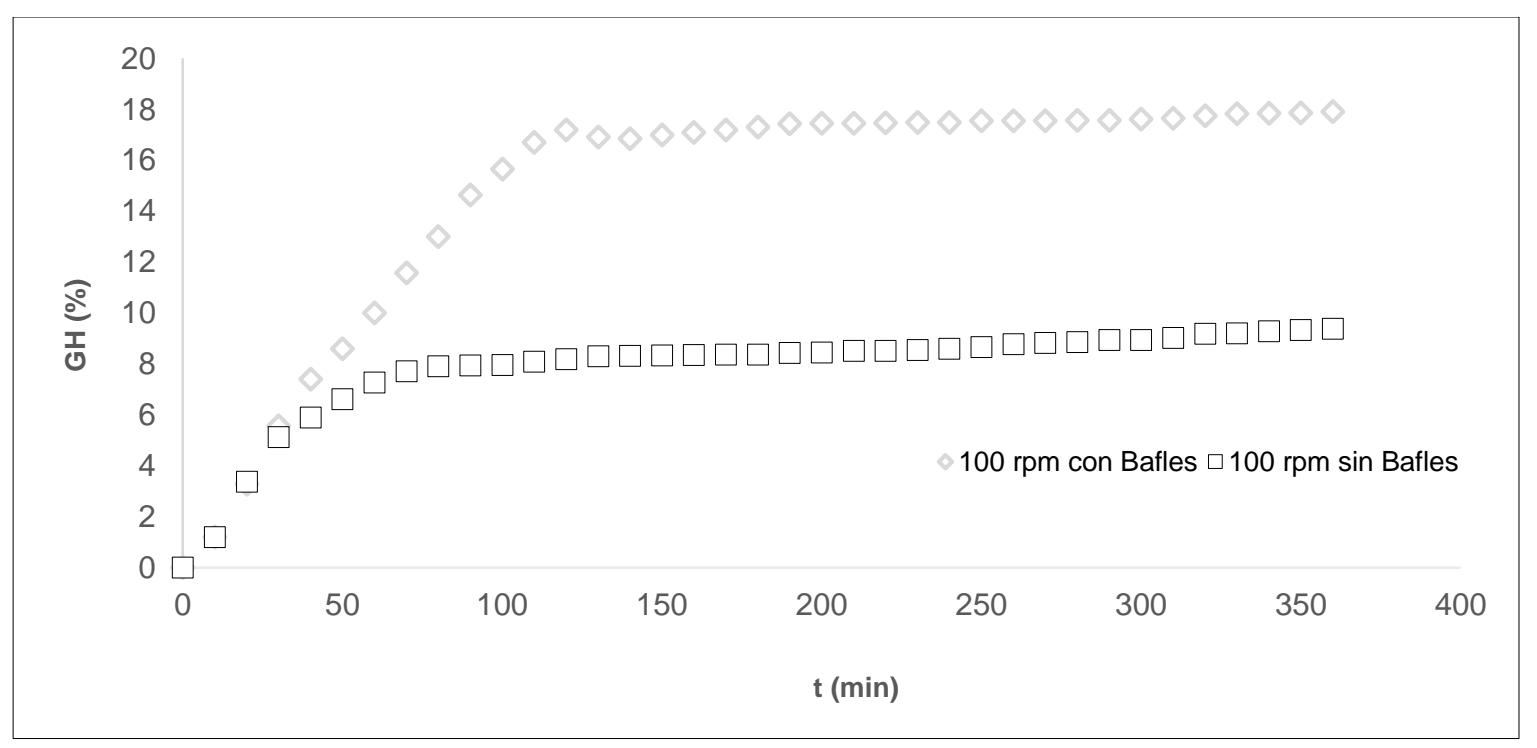

Fig. 3. Efecto de la presencia de bafles sobre el GH (\%) en la hidrólisis con Alcalasa 2.4L de VTA en función del tiempo $\left(45^{\circ} \mathrm{C}\right.$ y $\left.\mathrm{pH}=8.5\right)$ en reactor de $7,5 \mathrm{~L}$. 


\section{CONCLUSIONES}

Bajos las condiciones del presente trabajo la Alcalasa 2.4L alcanza más altos GH que la Flavourzyme y Neutrasa. Además dicho GH en Alcalasa 2.4L, depende significativamente del pH y la temperatura, llegando a valores máximos con $\mathrm{pH} 8,5$ y $45^{\circ} \mathrm{C}$. El comportamiento de la reacción también se ve afectado por la velocidad de agitación y la presencia de deflectores en el reactor, así como por la escala de trabajo.

\section{NOTACIONES}

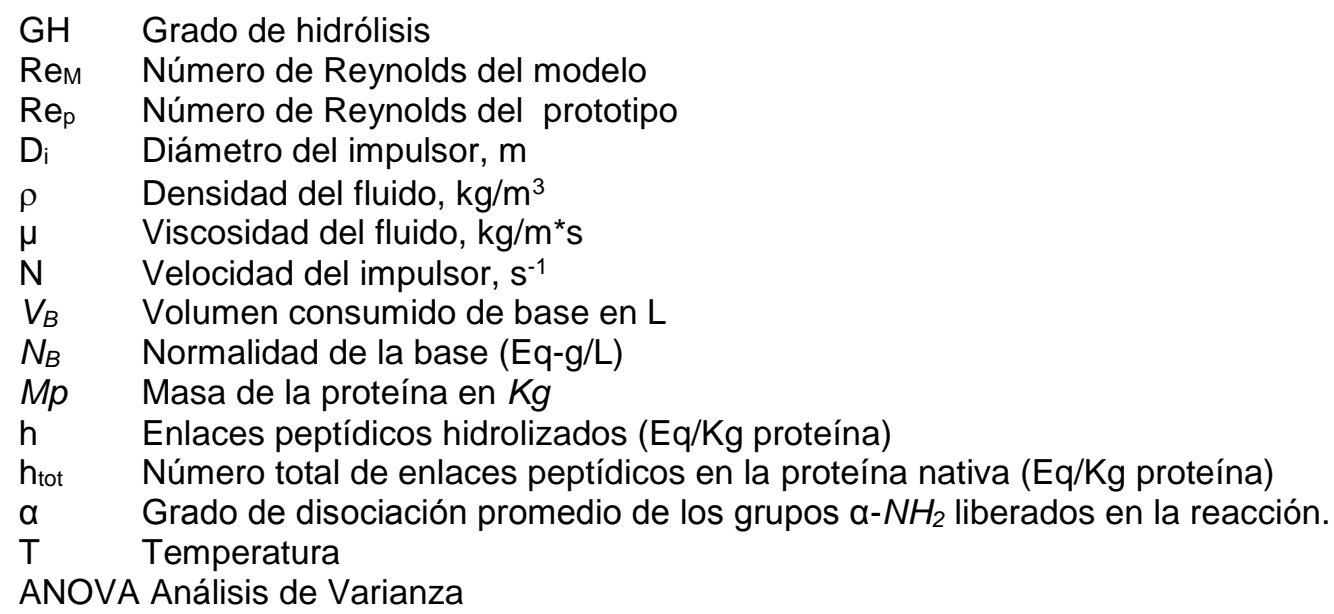

\section{AGRADECIMIENTOS}

Los autores del presente trabajo dan las gracias a la Gobernación de Antioquia, al Sistema General de Regalías de Colombia y a la Universidad de Antioquia, por el apoyo financiero, así como a la truchera San Felix por suministrar el sustrato de trabajo.

\section{REFERENCIAS}

Adler-Nissen, J., Enzymic hydrolysis of food proteins. 427, Elsevier Applied Science Publishers, Londres, Inglaterra (1986) Amiza, M.A., S. Ashikin y A. L. Faazaz, Optimization of Enzymatic Protein Hydrolysis from Silver Catfish (Pangasius Sp.) Frame, DOI: 10.15578/squalen.v9i3.79, Int Food Res J, 18(2), 775-781 (2011)

AOAC, 920.153, 930.15, 954.01, 960.39, Official Methods of Analysis of the Association of Official Analytical Chemists, 103-104, Arlington, USA (1990)

Belén Camacho, D. R. M. J. Moreno Álvarez y otros tres autores, Caracterización de un Hidrolizado Proteico Enzimático Obtenido del Pez Caribe Colorado (Pygocentrus cariba Humboldt, 1821), Interciencia, ISSN (on line): 2244 - 7776, 32(3), 188-193 (2007)

Bhaskar, N. y N.S. Mahendrakar, Protein Hydrolysate from Visceral Waste Proteins Of Catla (Catla catla): Optimization of Hydrolysis Conditions for a Commercial Neutral Protease, doi: 10.1016/j.biortech.2007.09.006, Bioresource Technol, 99(10), 4105-4111 (2008)

Chuesiang, P. y R. Sanguandeekul, Protein hydrolysate from tilapia frame: antioxidant and angiotensin I converting enzyme inhibitor properties. doi: 10.1111/ijfs.12762, Int J Food Sci Tech, 50(6), 1436-1444 (2015)

Colombié, S., A. Gaunand y B. Lindet, Lysozyme inactivation under mechanical stirring: Effect of physical and molecular interfaces, http://doi.org/10.1016/S0141-0229(01)00340-4, Enzyme Microb Tech, 28(9-10), 820-826 (2001)

Dekkers, E., S. Raghavan y otros dos autores, Oxidative Stability of Mahi Mahi Red Muscle Dipped in Tilapia Protein Hydrolysates, doi: 10.1016/j.foodchem.2010.06.088, Food Chem, 124(2), 640-645 (2011)

Deraz, S. F., Protein Hydrolysate from Visceral Waste Proteins of Bolti Fish (Tilapia nilotica): Chemical and Nutritional Variations as Affected by Processing pHs and Time of Hydrolysis, doi: 10.1080/10498850.2013.797534, J Aquat Food Prod T, 24(6), 614-631 (2014)

Forghani, B., A. Ebrahimpour y otros cuatro autores, Enzyme Hydrolysates from Stichopus Horrens as a New Source for Angiotensin-Converting Enzyme Inhibitory Peptides, http://dx.doi.org/10.1155/2012/236384, Evid-based Compl Alt, 2012 (Agosto 15), 1-9 (2012)

Gbogouri, G.A., M. Linder y otros dos autores, Influence of Hydrolysis Degree on the Functional Properties of Salmon Byproduct Hydrolysates, doi: 10.1111/j.1365-2621.2004.tb09909.x, J Food Sci, 69(8), 615-622 (2004)

Gelves, R., A. Benavides y Quintero, J. CFD Prediction of Hydrodynamic in the Scale Up of a Stirred Tank for Aerobic Processes, DOI: 10.4067/S0718-33052013000300005, Ingeniare: Revista Chilena de Ingeniería, 21(3), 347-361 (2013) 
Gómez, L.J. y J. E. Zapata, Efecto del Nivel de Grasa y Velocidad de Agitación en la Hidrolisis Enzimática de Vísceras de Tilapia Roja (Orechromis sp.), doi: 10.4067/S0718-07642017000400007, Inf. Tecnol., 28(4), 47-56 (2017)

Haney, E.F., S.C. Mansour y R.E.W. Hancock, Antimicrobial Peptides: An Introduction; in Methods in Molecular Biology, vol 1548, pp 3-22, Humana Press, New York, USA (2017)

He, S., C. Franco, y W. Zhang, Functions, Applications and Production of Protein Hydrolysates from Fish Processing CoProducts (FPCP), doi:10.1016/j.foodres.2012.10.031, Food Res Int, 50(1), 289-297 (2013)

Kechaou, E., J. Dumay y otros cinco autores, Enzymatic Hydrolysis of Cuttlefish (Sepia Officinalis) and Sardine (Sardina Pilchardus) Viscera Using Commercial Proteases: Effects on Lipid Distribution and Amino Acid Composition, doi: 10.1016/j.jbiosc.2008.10.018, J Biosci Bioeng, 107(2), 158-164 (2009)

Liu, Y., L. Xianghong y otros cuatro autores, Characterization of Structural and Functional Properties of Fish Protein Hydrolysates from Surimi Processing By-Products, doi:10.1016/j.foodchem.2013.11.089, Food Chem, 151(15), 459-465 (2014)

Martínez-Alvarez, O., S. Chamorro y A. Brenes, Protein Hydrolysates from Animal Processing By-Products as a Source of Bioactive Molecules with Interest in Animal Feeding: a Review, doi:10.1016/j.foodres.2015.04.005, Food Res Int, 73 (julio), 204-212 (2015)

Morales-Medina, R., R. Pérez-Gálvez y otros dos autores, Artificial Neuronal Network Modeling of the Enzymatic Hydrolysis of Horse Mackerel Protein Using Protease Mixtures, doi: https://doi.org/10.1016/j.bej.2015.10.009, Biochem Eng J, 105 (parte B), 364-370 (2016)

Palmqvist, B., A. Kadie y otros tres autores, Scale-Up of High-Solid Enzymatic Hydrolysis of Steam-Pretreatment Softwood: The Effects of Reactor Flow Conditions, https://doi.org/10.1007/s13399-015-0177-3, Biomass convers bior, 6(2), 173$180(2016)$

Pérez-Gálvez R., M.C. Almécija y otros tres autores, Bi-Objective Optimisation of the Enzymatic Hydrolysis of Porcine Blood Protein, doi: 10.1016/j.bej.2010.12.004, Biochem Eng J, 53(3), 305-10 (2011)

Roslan, J., S.M. Mustapa y otros dos autores, Optimization of Enzymatic Hydrolysis of Tilapia (Oreochromis Niloticus) Byproduct Using Response Surface Methodology, Int Food Res J, 22(3), 1117-1123 (2015)

Salwanee, S., W. M. Wan Aida y otros tres autores, Effects of Enzyme Concentration, Temperature, pH and Time on the Degree of Hydrolysis of Protein Extract from Viscera of Tuna (Euthynnus Affinis) by Using Alcalase, Sains Malays, 42(3), 279-287 (2013)

See, S.F., L.L. Hoo y A. S. Babji, Optimization of Enzymatic Hydrolysis of Salmon (Salmo Salar) Skin by Alcalase, Int Food Res J, ISSN (Online): 2231 7546, 18(4), 1359-1365 (2011)

Shahidi, F. y P. Ambigaipalan, Novel Functional Food Ingredients from Marine Sources, doi:10.1016/j.cofs.2014.12.009, Curr Opin Food Sci, 2(abril), 123-129 (2015)

Shi, D., Z. He y W. Qi, Lumping Kinetic Study on the Process of Tryptic Hydrolysis of Bovine Serum Albumin, doi:10.1016/j.procbio.2004.07.009, Process Biochem, 40(5), 1943-1949 (2005)

Silva, J.F.X., K. Ribeiro y otros tres autores, Utilization of tilapia processing waste for the production of fish protein hydrolysate, doi: http://dx.doi.org/10.1016/j.anifeedsci.2014.06.010, Anim Feed Sci Tech, 196(octubre), 96-106 (2014)

Souissi, N., A. Bougatef y otros dos autores, Biochemical and Functional Properties of Sardinelle (Sardinella Aurita) ByProduct Hydrolysates, Food Technol Biotech, ISSN (on line): 1334-2606, 45(2), 187-194 (2007)

Zhu, K. X, X. P Wang y X. N. Guo, Isolation and Characterization of Zinc-Chelating Peptides from Wheat Germ Protein Hydrolysates, doi: 10.1016/j.jff.2014.10.030, J Funct Foods, 12(enero), 23-32 (2015) 